\title{
Effects of different nutrient management on soil in long-term experiments
}

\author{
József Tibor ARANYOS - Ibolya DEMETER - Viktória OROSZ - Attila TOMÓCSIK - \\ István HENZSEL \\ University of Debrecen Research Institute of Nyíregyháza; H-4400 Nyíregyháza Westsik Vilmos út 4-6 \\ E-mail: aranyostibi@gmail.com, ibolyad85@gmail.com, orosz.viki@agrunideb.hu, tomocsik@gmail.com, henzsel@agrunideb.hu
}

Keywords: long-term experiment, climate change, soil respiration, nutrient management

\section{Introduction}

Examination of the effects of different nutrient management practices on soil is very important, because the changes in soil parameters are the result of long-term processes. For studying the effects of different fertilization methods, the long-term experiments provide excellent opportunities. Climate change and the possible solutions for stopping it are important questions of research and agriculture. Contribution of the agriculture to the climate change is $10-12 \%$, but the decrease of the greenhouse gas emission of this sector is very important. The soil is one of the largest carbon reservoirs. The soil respiration (the flow of $\mathrm{CO}_{2}$ into the atmosphere) is the major component of the element circulation of the Earth, thus it plays an important role in climate change. Soil respiration is primarily determined by the physical and chemical properties of the soil. The nutrient supplying methods of agricultural lands have strong effect on soil, depending both on the soil type and on the duration of the treatment. It is expected, that global warming will have an impact on soil respiration and has a positive feedback. For complex evaluation it is very important to understand soil respiration process and its connections with other soil properties (Reich and Schlesinger, 1992; Jensen et al., 1996; Hanson et al. 2000; Fang and Moncrieff, 2001).

\section{Materials and methods}

The research was conducted in Westsik's crop rotation experiment and in the sewage sludge compost experiment at the city of Nyíregyháza (Hungary). The Westsik's crop rotation experiment represents the classical farming systems of Eastern Hungarian Region, which is appropriate for studying long-term effects of different nutrient supplies (straw, farmyard and green manure) from 1929. The small-plot sewage sludge compost experiment was established in 2003. The aim of the research was to study the effect of different fertilization methods on soil respiration and the possible correlations between soil physical, chemical properties and the soil carbon-dioxide emission. Measurement of soil respiration was done by LCi-SD type portable $\mathrm{CO}_{2}$ measuring equipment, which measured the $\mathrm{CO}_{2}$ concentration parallel with soil temperature. Measurements were carried out in 2017 in rye, in three replicates. Statistical analysis of data was carried out using the one-way ANOVA test and correlation analysis. The means were compared with Tukey's test.

\section{Results and discussion}

The intensity of soil respiration was the lowest in the control, and it was significantly higher in the other studied crop rotations (Figure 1). The highest soil respiration was measured in the sewage sludge compost treatment. The organic matter content of soil also increased in all studied treatments except in the control. So the organic matter treatments 
had a significant effect on carbon dioxide emission of soil, thereby the intensity of soil respiration increased. However, the different type of organic matter added to the soil resulted in different $\mathrm{CO}_{2}$ efflux of soil. The organic matter input also had a positive effect on the chemical $(\mathrm{pH})$ and physical properties (bulk density) of soil. Strong correlation was found between the soil respiration and other studied soil properties (organic matter content, $\mathrm{pH}$, moisture content).

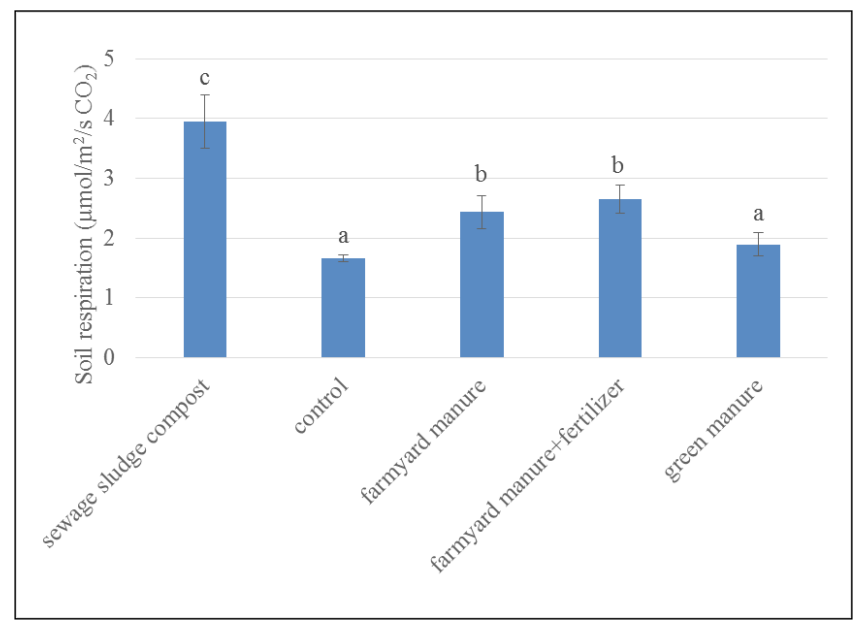

Figure 1: Changes in soil respiration by the effects of different nutrient supplies in 2017

\section{Conclusions}

As expected, there was a significant effect of different fertilization methods on soil respiration and there were correlations between the rate of soil carbon-dioxide emission and some measured physical and chemical soil properties. In the treatments, in which the soil was treated by organic matter, the $\mathrm{CO}_{2}$ emission of soil was higher. This could indicate greater microbial activity, which can result in high quantity of available nutrients for plants. In the future further tests and calculation of exact carbon balance are required for understanding soil respiration processes and for increasing the quantity of carbon stored in the soil.

\section{Acknowledgement}

This research was realized in the frames of TÁMOP 4.2.4. A/2-11-1-2012-0001 "National Excellence Program-Elaborating and operating an inland student and researcher personal support system convergence program". The project was subsidized by the European Union and co-financed by the European Social Fund

\section{References}

Fang, C. and Moncrieff, J.B. (2001): The dependence of soil CO2 efflux on temperature. Soil Biology and Biochemistry, 33, 155-165. https://doi.org/10.1016/s0038-0717(00)00125-5

Hanson, P.J., Edwards, N., Garten, C.T. \& Andrews, J.A. (2000): Separating root and soil microbial contributions to soil respiration: A review of methods and observations. Biogeochemistry. 48: 115-146.

Jensen, L.S., Müller, T., Tate, K.R., Ross, D.J., Magid, J., Nielsen, N.E. (1996): Soil surface CO2 flux as an index of soil respiration in situ: a comparison of two chamber methods. Soil Biology \& Biochemistry. 28: $1297-$ 1306. https://doi.org/10.1016/s0038-0717(96)00136-8

Reich J.W. and Schlesinger W.H. (1992): The global carbon-dioxide flux in soil respiration and its relationship to climate. Tellus. 44: 81-99. https://doi.org/10.1034/j.1600-0889.1992.t01-1-00001.x 